\title{
OBSERVATORIO IBEROAMERICANO
} DEL DESARROLLO LOCAL Y LA ECONOMIA SOCIAL

O ENGENHEIRO DE SEGURANÇA DO TRABALHO COMO GARANTIDOR DE CONDIÇÕES LABORAIS SALUBRES PARA O PEQUENO PRODUTOR RURAL IRRIGANTE

\author{
Alexsandro Lima Sampaio1 \\ sampaiotst@gmail.com \\ Camila Nunes Marques2 \\ camilanunes_m@hotmail.com \\ Orlando Moreira de Melo Filho3 \\ orlandodmelo@yahoo.com.br \\ Francisco Carlos Xeres 4 \\ carlosxeres@hotmail.com
}

Para citar este artículo puede utilizar el siguiente formato:

Alexsandro Lima Sampaio, Camila Nunes Marques, Orlando Moreira de Melo Filho y Francisco Carlos Xeres: "O engenheiro de segurança do trabalho como garantidor de condições laborais salubres para o pequeno produtor rural irrigante", Revista OIDLES, Vol 14 № 29 (diciembre 2020). En línea:

https://www.eumed.net/es/revistas/oidles/vol-14-no-29-diciembre-2020/produtor-rural-irrigante

\section{RESUMO}

O Brasil teve um crescimento acelerado da agricultura na última década e, em consequência disso, ocorreu a produção e utilização de um grande número de novos defensivos agrícolas, tornando o Brasil um dos maiores consumidores desse insumo no mundo. Objetivou-se nesse trabalho, de modo geral, contextualizar a discussão sobre o desenvolvimento da agricultura no Brasil e no Mundo e o consequente aumento na utilização dos chamados defensivos agrícolas. Como objetivo específico, procedeu-se a caracterização do pequeno produtor irrigante de um projeto público de irrigação de acordo com a nova Lei de Irrigação, e por último, elencou-se as atribuições dos Engenheiros de Segurança do Trabalho na sua atuação relativa aos cuidados no manuseio e aplicação dos agrotóxicos na defesa e garantia de integridade laboral do

1 Engenheiro Ambiental e Sanitarista - UNIFANOR.

2 Engenharia Ambiental - Universidade Federal do Ceará.

3 Engenheiro Agrônomo - M. Sc. Agronomia/Fitotecnia - Universidade Federal do Ceará.

4 Engenheiro Agrônomo - Esp. Engenharia de Segurança do Trabalho - Professor Orientador. 
trabalhador rural. Para a concretização do presente trabalho foi adotado o procedimento metodológico da pesquisa investigativa através de um levantamento bibliográfico criterioso sobre a temática abordada em livros, legislação oficial, publicações científicas, normas e resoluções, dentre outros; como forma de garantir respaldo técnico e científico para o presente artigo. As considerações finais destacam que é dever do Engenheiro de Segurança do Trabalho voltar-se, precipuamente, para a proteção do trabalhador rural em todas as unidades laborais no que se refere a questões de segurança do trabalho. Vê-se, nesse profissional, um garantidor efetivo da segurança laboral do pequeno produtor rural irrigante dos Projetos Públicos de Irrigação-PPIs.

Palavras-chave: Defensivos agrícolas. Agricultura. Segurança laboral.

\section{EL INGENIERO DE SEGURIDAD LABORAL COMO GARANTÍA DE SALUDAS CONDICIONES LABORALES PARA EL PEQUEÑO PRODUCTOR RURAL IRRIGANTE}

\section{RESUMEN}

Brasil ha tenido un crecimiento acelerado de la agricultura en la última década y, como resultado, ha habido la producción y uso de una gran cantidad de nuevos pesticidas, lo que convierte a Brasil en uno de los mayores consumidores de este insumo en el mundo. El objetivo de este trabajo fue, en general, contextualizar la discusión sobre el desarrollo de la agricultura en Brasil y en el mundo y el consecuente incremento en el uso de los llamados plaguicidas. Como objetivo específico, se realizó la caracterización del pequeño productor regantes de un proyecto público de riego de acuerdo a la nueva Ley de Riegos, y por último, se enumeraron las atribuciones de los Ingenieros de Seguridad Laboral en su desempeño relacionado con el cuidado en el lugar de trabajo. manejo y aplicación de plaguicidas en la defensa y garantía de la integridad laboral de los trabajadores rurales. Para el desarrollo del presente trabajo se adoptó el procedimiento metodológico de la investigación investigativa mediante un cuidadoso relevamiento bibliográfico sobre el tema abordado en libros, legislación oficial, publicaciones científicas, normas y resoluciones, entre otros; como forma de garantizar el soporte técnico y científico de este artículo. Las consideraciones finales resaltan que es deber del Ingeniero en Seguridad Ocupacional enfocarse, principalmente, en la protección de los trabajadores rurales en todas las unidades de trabajo en lo que respecta a los temas de seguridad ocupacional. En este profesional, se ve un garante eficaz de seguridad laboral para el pequeño productor rural regantes de Proyectos Públicos de Riego-PPI.

Palabras clave: Plaguicidas. Agricultura. Seguridad Ocupacional. 


\section{THE WORK SAFETY ENGINEER AS GUARANTEE OF HEALTHY WORKING CONDITIONS FOR THE SMALL IRRIGATING RURAL PRODUCER \\ ABSTRACT}

Brazil has had an accelerated growth in agriculture in the last decade and, as a result, there has been the production and use of a large number of new pesticides, making Brazil one of the largest consumers of this input in the world. The objective of this work was, in general, to contextualize the discussion about the development of agriculture in Brazil and in the World and the consequent increase in the use of the so-called pesticides. As a specific objective, the characterization of the small irrigating producer of a public irrigation project was carried out according to the new Irrigation Law, and lastly, the duties of the Work Safety Engineers were listed in their work related to care in the workplace. handling and application of pesticides in the defense and guarantee of labor integrity of rural workers. In order to carry out the present work, the methodological procedure of investigative research was adopted through a careful bibliographic survey on the subject addressed in books, official legislation, scientific publications, rules and resolutions, among others; as a way to guarantee technical and scientific support for this article. Final considerations highlight that it is the duty of the Occupational Safety Engineer to focus, primarily, on the protection of rural workers in all work units with regard to occupational safety issues. In this professional, one sees an effective guarantor of job security for the small irrigating rural producer of Public Irrigation Projects-PPIs.

Keywords: Pesticides. Agriculture. Occupational safety.

\section{INTRODUÇÃO}

É de conhecimento geral que todas as atividades agrícolas são desenvolvidas em contato direto com o meio ambiente, e dessa interação muitos fatores bióticos e abióticos podem sofrer algum tipo de interferência em seus aspectos fisiológicos e ambientais.

Assim sendo, solos, água, ar e seres vivos, como integrantes desse meio, estão diretamente relacionados com a qualidade e suficiência dos alimentos e de outras matérias primas a serem produzidas.

Entender que todos esses fatores estão inter-relacionados e que, qualquer atividade que venha a interferir em um deles, poderá afetar os demais e, consequentemente, influir no equilíbrio de toda a cadeia produtiva, é prioritário.

Por isso, antes de se colocar em prática a implantação de um projeto agrícola, precisase primeiramente saber mais a respeito do local onde o mesmo será implementado, conhecendo melhor o que cada área possui de ambiente natural e social, de modo que permita 
a compreensão e avaliação de possíveis impactos sobre o ambiente selecionado para implantação do empreendimento e como minimizá-los.

Portanto, o manejo racional das atividades relacionadas ao desenvolvimento sustentado de uma área agrícola apta para agricultura irrigada, demanda estudos que levem em consideração os aspectos econômicos, técnicos, sociais e ecológicos e, principalmente humano, de cada região, identificando-se todos os possíveis impactos ao meio ambiente e as pessoas nele inseridas e as possíveis ações mitigadoras de cada interferência.

Ao tempo em que a atividade de agricultura se torna essencial à sociedade moderna, com todos os benefícios econômicos e sociais que proporcionam, principalmente no quesito segurança alimentar da população, a implantação de novos projetos agrícolas traz consigo uma série de impactos ao meio ambiente, sejam eles, sobre o meio físico, biótico e/ou antrópico.

Assim sendo, discussões ambientais, sociais e de segurança dos trabalhadores rurais se tornam mais frequentes, principalmente no que se trata de um dos insumos agrícolas mais utilizados atualmente, os defensivos agrícolas, uma vez que estes influenciam diretamente no ambiente em que se inserem de maneiras diferenciadas.

Dados estatísticos comprovam que o consumo de defensivos agrícolas tem aumentado consideravelmente em todo o planeta e, a cada dia, novos produtos são colocados no mercado para controlar novas pragas, doenças e ervas daninhas, tornando essa dependência cada vez mais frequente.

Atualmente o Brasil se consolida como um dos maiores consumidores de agrotóxicos do mundo.

A utilização em grande escala desse tipo de produto promove consequências graves à saúde da população como um todo, mas principalmente traz como consequências, graves problemas à saúde dos trabalhadores e de toda população, além dos danos à natureza pela degradação dos recursos naturais não renováveis, desequilíbrio e destruição da fauna e flora e poluição das águas, ar e solos.

É característico de grandes projetos de produção agrícolas que suas implementações e desenvolvimento estejam associadas à geração de uma gama de impactos adversos sobre o meio ambiente e, principalmente, ao homem, os quais só podem ser minorados através da incorporação de medidas de proteção ambiental e segurança das atividades laborais do trabalhador rural por parte das empresas e/ou empreendedores agrícolas. 
Comumente, a análise ambiental deste tipo de empreendimento deverá identificar inicialmente um número de impactos adversos superior aos benefícios gerados, o que é o caso do uso indiscriminado de defensivos agrícolas sem os devidos cuidados com o ente mais vulnerável dessa imensa cadeia produtiva, o produtor rural, que no nosso caso específico daremos ênfase aos os pequenos produtos irrigantes dos projetos públicos de irrigação.

O objeto de discussão desse trabalho diz respeito a utilização dos chamados defensivos agrícolas, que devido à toxidade de alguns produtos podem provocar muitos efeitos deletérios ao homem e ao meio ambiente. Neste ínterim estão inseridos, e mais susceptíveis, os pequenos trabalhadores rurais.

Estes são os mais expostos a esse tipo de produto e necessitam de olhar especial por parte daqueles que legislam e dos que fiscalizam todos os processos produtivos que fazem uso deste tipo de insumo.

Neste sentido procurou-se dar ênfase a legislação oficial sobre defensivos agrícolas, sua aplicação e controle e, principalmente, a contribuição efetiva dos Engenheiros de Segurança do Trabalho, na avaliação quanto aos cuidados no manuseio, aplicação desse insumo agrícolas e na prevenção dos acidentes e intoxicações com este tipo de produto.

Esse profissional, que tem entre suas atribuições funcionais atuar ativamente na defesa e garantia de integridade laboral daqueles que exercem quaisquer atividades que envolvam algum tipo de riscos em suas ações, tem também no trabalhador rural, seja ele irrigante ou não, como foco de sua área de atuação.

Nesse trabalho deu-se ênfase ao trabalho rural, que no caso específico discorreu-se sobre o pequeno produtor irrigante de um projeto público de irrigação, em seus aspectos de produção e, principalmente, a atuação do Engenheiro de Segurança do Trabalho (EST) como garantidor da proteção laboral quanto a utilização e manuseio correto no uso defensivos agrícolas pelos agricultores irrigantes, como forma de garantir sua segurança no exercício de suas atividades produtivas.

O artigo ficou estruturado da seguinte maneira: após a introdução tem-se a fundamentação teórica que abordou os seguintes tópicos: no primeiro foi feito um breve histórico referente à agricultura no Brasil e no Mundo; no segundo foram abordados os agrotóxicos apresentando-se a sua definição e a sua classificação; o terceiro foi dedicado à discussão sobre o arcabouço legal sobre defensivos agrícolas; no quarto descreveu-se os tipos de agrotóxicos; no quinto destacou-se a importância dos pequenos produtores rurais na segurança alimentar do Brasil; no sexto ressaltou-se a Engenharia de Segurança do Trabalho; no sétimo foram abordadas as Normas Regulamentadoras. Em seguida apresentou-se os 
procedimentos metodológicos adotados nesta pesquisa e, por fim, desenvolveu-se as considerações finais e as referências que serviram de amparo teórico para o desenvolvimento deste artigo científico.

\section{METODOLOGIA}

Para a concretização do presente trabalho foi adotado o procedimento metodológico da pesquisa investigativa por meio de um levantamento bibliográfico criterioso sobre os temas abordados como forma de garantir respaldo técnico e científico para os temas objeto do presente artigo.

Para tanto foram analisadas fontes da literatura especializada composta de livros, publicações científicas, normas e resoluções de entes públicos nacionais, legislação federal sobre os temas e pesquisas on-line.

Inicialmente procurou-se dar ênfase a conceituação de defensivos agrícolas, sua classificação toxicológica, suas implicações e formas de manuseio e controle.

Nesse sentido, as contribuições de Moraes (2019) e Sousa (2020) foram muito importantes para a conceituação do que são os defensivos agrícolas, também conhecidos como agrotóxicos.

Contribuições relevantes também foram colhidas de informações documentais de reconhecidos entes públicos como, do Instituto Brasileiro do Meio Ambiente e dos Recursos Naturais Renováveis - IBAMA; Ministério da Agricultura (MAPA); da Agência nacional de vigilância Sanitária - ANVISA, que nos presenteou com a mais recente classificação dos agrotóxicos.

Num segundo momento, procurou-se dar ênfase às questões relacionadas à segurança laboral dos trabalhadores de um modo geral.

Nesse ínterim, muitas contribuições foram levantadas do Bureau Internacional do Trabalho, principalmente no que consiste as ações necessárias à garantia da saúde e segurança do trabalhador.

Ainda fazendo uso da legislação oficial sobre segurança do trabalho (Leis e NRs), promoveu-se uma avaliação pormenorizada da NR 31, que trata especificamente da segurança e saúde no trabalho na agricultura, pecuária, silvicultura, exploração florestal e aquicultura. 
Nessa avaliação consideramos à contribuição efetiva dos Engenheiros de Segurança do Trabalho, na avaliação quanto aos cuidados no manuseio e na aplicação dos agrotóxicos e, principalmente, na prevenção dos acidentes e intoxicações com este tipo de produto, podendo atuar ativamente na defesa e garantia de integridade laboral daquele que é o principal afetado por possíveis acidentes, o trabalhador rural.

\section{FUNDAMENTAÇÃO TEÓRICA}

\subsection{Breve Histórico: A Agricultura no Brasil e no Mundo}

Ao longo de nossa história, o setor agrícola no Brasil passou por diversos ciclos e transformações, tendo como princípio a economia canavieira, caracterizada com o grande crescimento da produção de cana-de-açúcar no País, o que ocorreu no período do BrasilColônia, até o presente momento, com a expansão das culturas do café, soja, dentre outras.

O Brasil é considerado uma das maiores potências agrícolas do mundo, ocupando atualmente a posição de $2^{\circ}$ maior produtor de alimentos do planeta, depois apenas dos Estados Unidos, e com potencial para, em pequeno lapso temporal, se tornar o primeiro do ranking.

Mas apesar do aumento considerável da capacidade de produção e de oferta de alimentos no Brasil e no Mundo faz necessário enfatizar que o aumento da produtividade agrícola, associados aos cultivos em sistema de monocultura e ao agronegócio de exportação também é causador de inúmeros impactos socioambientais e à saúde de muitos trabalhadores rurais.

Paralelamente a isso, o país também se encontra no topo quando o assunto é comercialização de agrotóxicos, substâncias químicas ou biológicas que conferem proteção às lavouras contra o ataque e a proliferação de pragas, como insetos, fungos, bactérias, vírus, ácaros, nematoides e ervas daninhas (Moraes, 2019).

Segundo Moraes (2019), o uso de agrotóxicos no Brasil se intensificou substancialmente a partir do início dos anos 1990, fazendo do país o segundo ou terceiro maior consumidor do mundo, uma tendência semelhante à dos demais países do Mercosul 
A utilização de insumo agrícola é concentrada em algumas lavouras, especialmente soja, milho e cana-de-açúcar, e é também concentrada espacialmente, sobretudo nas regiões Centro-Oeste, Sul e no estado de São Paulo (Sousa, 2020).

Sousa (2020) destaca ainda que a produção desse agroquímico é dominada por poucas empresas, onde as cinco maiores produtoras respondem por mais de $50 \%$ do total de agrotóxicos consumidos no país.

Houve também um expressivo aumento no uso entre os anos de 2010 e 2017. No ano de 2017, foram usados no Brasil cerca de 540 mil toneladas de agroquímicos, aproximadamente $50 \%$ a mais que em 2010 segundo informações divulgadas pelo Instituto Brasileiro do Meio Ambiente e dos Recursos Naturais Renováveis (IBAMA).

Mas é válido ressaltar que apesar do grande comércio de agrotóxicos no país, o seu uso por hectare é baixo em relação a outros países, sendo possível afirmar que a produtividade do Brasil é elevada e o uso de agrotóxicos por área produzida torna-se baixo (Sousa, 2020).

Outro fator relevante ligado ao uso de agrotóxicos é a questão da evolução tecnológica ocorrida no campo.

Os instrumentos empregados atualmente no setor agropecuário favoreceram o aumento da produtividade e para isso é preciso um controle maior dos possíveis danos a uma lavoura.

A prática da monocultura também propicia o uso de agrotóxicos, porque também favorece o ciclo de pragas e doenças (Vasconcelos, 2018).

No início de 2019, o Ministério da Agricultura aprovou o registro de agrotóxicos de elevada toxicidade. Foram registrados no Brasil cerca de 450 agrotóxicos.

Desses, apenas 52 apresentam baixa toxicidade. A ANVISA manifestou que agrotóxicos banidos em países como China, Estados Unidos e países da União Europeia têm atualmente como principal destino o Brasil. Aqui são usados pelo menos dez produtos banidos nesses países (Bombardi, 2017; Sousa, 2020).

Essa flexibilização em torno do uso de agrotóxicos, segundo Sousa (2020), foi e é motivo de diversos debates entre ambientalistas e diversos órgãos que criticam a permissividade do governo brasileiro em relação ao uso de agrotóxicos. 
Sendo os agricultores e trabalhadores rurais os grupos mais afetados pela exposição aos defensivos agrícolas, o risco de contaminação humana e do meio ambiente por esse tipo de produto pode ocorrer desde os processos de fabricação até a destinação final das embalagens vazias.

Segundo a ANVISA, a exposição aos defensivos agrícolas que estes produtos representam podem ocorrer através de contato de forma direta ou indireta, seja por contato do produto com alguma parte do corpo humano, ou pela absorção pela pele, narinas ou de forma oral (Brasil, 2019).

Do outro lado, encontram-se os ruralistas, que acreditam ser inevitável a utilização dos defensivos agrícolas, visto que a produtividade brasileira no setor de produção agrícola depende do uso dessas substâncias.

Essa estratégia de justificar a necessidade de utilização dos agrotóxicos advém da imposição da racionalidade tecnocrática midiática sobre a opinião pública e trabalhadores com a justificativa de que toda técnica agrícola que propicie solucionar o desafio de alimentar o mundo é moralmente justificável, sem levar em consideração os riscos que a utilização de determinados produtos químicos possa vir a causar algum dano aos seres humanos de modo geral.

\subsection{Agrotóxicos: Definição e Classificação}

De uso inicialmente militar, os agrotóxicos foram largamente utilizados como arma bélica de grande poder destrutivo da segunda guerra mundial. A partir de então, passaram a ser utilizados no campo e em atividades de saúde pública no controle de endemias causadas por insetos.

Tendo como produto inicial o DDT (diclorodifeniltricloroetano) que foi considerado, na época, uma revolução no que diz respeito ao controle de pragas na agricultura (Porto; Soares, 2012).

Os agrotóxicos, também conhecidos como agroquímicos, pesticidas ou defensivos agrícolas, são produtos bastante utilizados na agricultura, principalmente em sistemas de monoculturas, como forma de conter pragas, eliminar doenças e acabar com plantas invasoras que podem prejudicar o desenvolvimento de uma plantação (Santos, 2020).

Mas é válido ressaltar que o uso de agrotóxicos também ocorre em produções de menor escala, visto que há necessidade de utilizar os defensivos agrícolas visando a quebrar o 
ciclo das pragas e diminuir os riscos de danos à plantação para garantir o aumento da produtividade.

Apesar dos benefícios para a agricultura, os agrotóxicos também podem ser nocivos para os seres vivos e podem desencadear contaminação e poluição do solo, água e até mesmo do ar (Santos, 2020).

E seu uso excessivo e incorreto pode causar sérios danos ao meio ambiente, como contaminação do solo, do lençol freático, dos produtos cultivados e, consequentemente, provocar danos ao meio ambiente e à saúde dos trabalhadores (Santos, 2020).

Atualmente, na agricultura moderna, é impossível se falar em produção em larga escala, sem a utilização de defensivos agrícolas.

Mas esse modelo hegemônico do agronegócio associado ao uso intensivo de pesticidas agrícolas, tem gerado muitos aspectos negativos, como impactos sócias, ambientais e sanitários que na maioria das vezes não são incorporados pela cadeia produtiva como um todo, vindo a ser pagos pela sociedade por meio de gastos públicos (Porto; Soares, 2012).

Segundo Carneiro et al. (2015), esse cenário ainda é mais grave em países em desenvolvimento, onde ocorrem a maioria dos processos de intoxicações de produtores rurais com muitas mortes, tendo em vista o nível educacional associado aos poucos cuidados com o uso, assim como a regulamentação e os métodos de controle, frequentemente negligenciados e/ou inexistentes.

A tecnologia de produção atual faz uso destes produtos em todas as fases de cultivo, desde antes da germinação, no preparo dos solos, até no armazenamento das produções, o que torna praticamente impossível o cultivo intensivo de culturas livres da aplicação desse insumo (Santos, 2020).

Segundo Vasconcelos (2018), dentre os 10 primeiros produtos com maior participação no total das exportações brasileiras, tivemos: soja, açúcar, carne de frango, farelo de soja, carne bovina, celulose e café em grão, o que aumenta consideravelmente nossa busca pelos mais diferentes tipos de insumos para que tenha uma maior produtividade de produtos agrícolas.

As produções agrícolas campeãs no uso de agrotóxicos foram, segundo o Sindicato Nacional da Indústria de Produtos para Defesa Vegetal-SINDIVEG (2017): 1 Soja; 2 Cana-deaçúcar; 3ํMilho e em 4ํA Algodão (Sousa, 2020). 
Ainda de acordo com Tooge (2020) só neste ano já foram registrados 315 registros de novos agrotóxicos, conforme compilação de dados de publicações oficiais retiradas Diário Oficial da União, que é por onde a reportagem se baseia.

Percebe-se que desde 2005, quando o governo começou a compilar os dados de registro de pesticidas, 2020 perde apenas para 2019 - ano em que o país teve liberação recorde de agrotóxicos.

Segundo compilação de dados retirados do Diário Oficial da União o G1 apresenta o quadro de agrotóxicos liberados para comercialização no Brasil no período de 2002 a 2019, conforme a figura 1 , na próxima página.

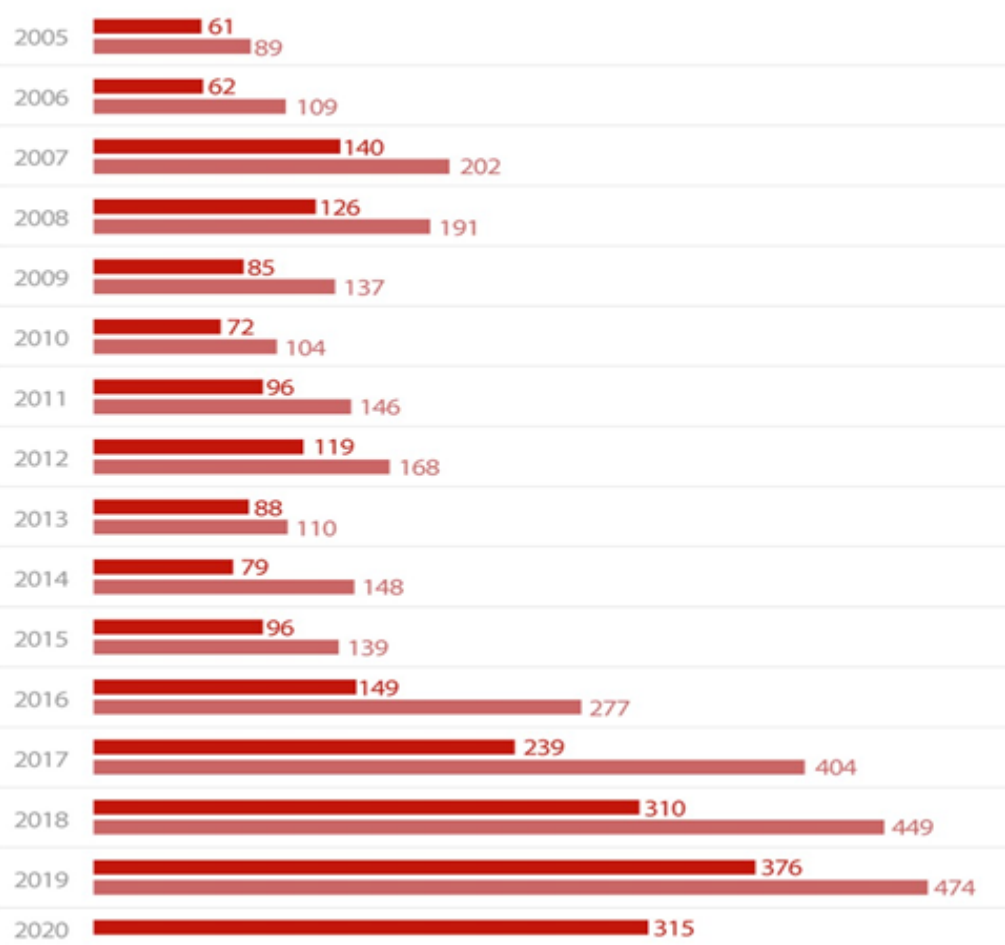


Figura 1 - Registro de Agrotóxicos no Brasil.

Fonte: Tooge (2020). Governo libera o registro de 31 agrotóxicos genéricos para uso dos agricultores. São Paulo: G1. Disponível em: https://g1.globo.com/economia/agronegocios/noticia/2020/09/23/governo-libera-o-registro-de31-agrotoxicos-genericos-para-uso-dos-agricultores.ghtml. Consultado em: 23 de setembro de 2020.

Nesse contexto, mesmo que o crescimento de forma exponencial da população exija também um crescimento da produção agrícola na mesma proporção, tornando o uso dos defensivos agrícolas praticamente inevitável, torna-se imperioso aos Engenheiros de Segurança do Trabalho, detentores do conhecimento e aplicabilidades das normas legais de garantias da salubridade das condições de trabalho, assegurar àqueles que necessitam de nossa orientação técnica e proteção, condições para o exercício pleno e seguro das atividades laborais de todos os envolvidos num sistema de produção agrícola.

\subsection{Arcabouço Legal sobre Defensivos Agrícolas}

Conhecida como Lei de Agrotóxicos, a Lei oㅜ 7.802, de 11 de julho de 1989, é o marco legal inicial sobre a fixação de diretrizes e normatização sobre esse insumo agrícola e dispõe sobre a pesquisa, a experimentação, a produção, a embalagem e rotulagem, o transporte, o armazenamento, a comercialização, a propaganda comercial, a utilização, a importação, a exportação, o destino final dos resíduos e embalagens, o registro, a classificação, o controle, a inspeção e a fiscalização de agrotóxicos, seus componentes e afins, e dá outras providências (Brasil, 1989).

De acordo com a Lei 7802/89, regulamentada pelo Decreto ㄲo 4074, de 04 de dezembro de 2002 e pelo Decreto № 5981 de 2006, define-se como agrotóxicos e afins: produtos e agentes de processos físicos, químicos ou biológicos, destinados ao uso nos setores de produção, no armazenamento e beneficiamento de produtos agrícolas, nas pastagens, na proteção de florestas, nativas ou plantadas, e de outros ecossistemas e de ambientes urbanos, hídricos e industriais, cuja finalidade seja alterar a composição da flora ou da fauna, a fim de preservá-las da ação danosa de seres vivos considerados nocivos, bem como as substâncias e produtos empregados como desfolhantes, dessecantes, estimuladores e inibidores de crescimento (Brasil, 2002). 
Extrai-se que a legislação brasileira é bastante ampla nesse sentido, identifica-se que ainda existe uma grande lacuna na fiscalização destes insumos, na produção, no controle da comercialização e informação ao usuário final e, principalmente, no que diz respeito à garantia de um ambiente salubre que garanta a segurança do trabalhador rural no exercício de suas atividades laborais.

\subsection{Tipos de Agrotóxicos}

Os agrotóxicos são usados com bastante frequência nas produções agrícolas e sua classificação tipológica está associada à natureza da praga que será combatida, ao grupo químico à qual pertence, bem como aos danos relacionados ao meio ambiente e à saúde humana, e, segundo Sousa (2020), são classificados em:

- Inseticidas: Combatem insetos. Exemplos: Aldrin, Carbofuran, Deltametrina.

- Fungicidas: Combatem fungos. Exemplos: Mancozeb, Binapacril, Brestam.

- Herbicidas: Combatem ervas daninhas. Exemplos: Profam, Diquat, Diclobenil.

- Desfolhantes: Combatem folhas indesejadas. Exemplos: Paraquat e Dinoseb.

- Fumigantes: Combatem bactérias nos solos. Exemplos: Dazomet e Cloropicrina.

Esses produtos têm atuação no controle e na proliferação de pragas, ervas daninhas e no combate a possíveis doenças associadas ao cultivo de determinadas espécies vegetais.

São compostos por substâncias químicas capazes de agir sobre a atividade fisiológica de insetos, fungos, vírus, nematoides e bactérias que estejam atacando cultivos agrícolas, atuando na proteção das lavouras, sendo considerado pelos produtores rurais um insumo de importância relevante para desenvolvimento de suas atividades agrícolas. 


\subsubsection{Classificação Toxicológica}

No Brasil os agrotóxicos recebem em seu rótulo uma classificação toxicológica, ou seja, descrevem o potencial de risco dos defensivos agrícolas à saúde humana. Essa classificação é feita por meio da diferenciação de cores e também por meio da dose de letalidade de cada um.

A Agência Nacional de Vigilância Sanitária/ANVISA aprovou, em julho do ano próximo passado, o "novo marco regulatório para agrotóxicos".

Essa medida que, além de atualizar e tornar mais claros os critérios de avaliação e classificação toxicológica desse tipo de produto no Brasil, com o estabelecimento de categorias e faixas de cores que vão facilitar consideravelmente a comunicação do perigo desses produtos.

Além disso, estabeleceu concomitantemente, mudanças importantes nos sistemas de rotulagem, com a adoção do uso de informações, palavras de alerta e imagens (pictogramas) que facilitam a identificação de perigo à vida e à saúde humana, itens fundamentais também para a segurança daqueles que atuam na ponta dos sistemas de produção, os trabalhadores.

O Sistema de Classificação Globalmente Unificado (Globally Harmonized System of Classification and Labelling of Chemicals - GHS), lançado em 1992, na ECO92, ainda não foi implementado em muitos países. Existe uma tendência de harmonização da classificação toxicológica e da implementação do GHS.

No Cenário Nacional a classificação toxicológica prevista pela Portaria ํ3/92 não está harmonizada com relação ao que é praticado no mundo.

O Brasil é o único país que estabeleceu a proibição do registro de produtos "cuja ação tóxica" seja maior do que os já registrados.

No GHS os resultados dos estudos toxicológicos de irritação dérmica e ocular e de sensibilização dérmica e inalatória não serão utilizados para fins de classificação toxicológica e sim utilizados para estabelecer a comunicação do perigo dos produtos (Brasil, 2019).

De acordo com o Ministério da Agricultura (MAPA, 2020), um outro quesito relacionado que foi considerado relevante pela comunidade científica na nova sistematização diz respeito ao uso de uma caveira no rótulo dos alimentos. 
Pelas regras antigas, a imagem constava nas embalagens de todos os tipos de veneno. De acordo com a nova classificação, a imagem só será obrigatória apenas para as duas categorias consideradas mais perigosas.

O Sistema de Classificação Globalmente Unificado (Globally Harmonized System of Classification and Labelling of Chemicals - GHS), lançado em 1992, na ECO92, ainda não foi implementado em muitos países. Existe uma tendência de harmonização da classificação toxicológica e da implementação do GHS.

Nesse sentido, de acordo com o novo marco regulatório da ANVISA (Brasil, 2019, p. 35) a classificação em função da toxicidade aguda deve ser determinada e identificada com os respectivos nomes das categorias e cores nas faixas do rótulo dos produtos, de acordo com o estabelecido a seguir:

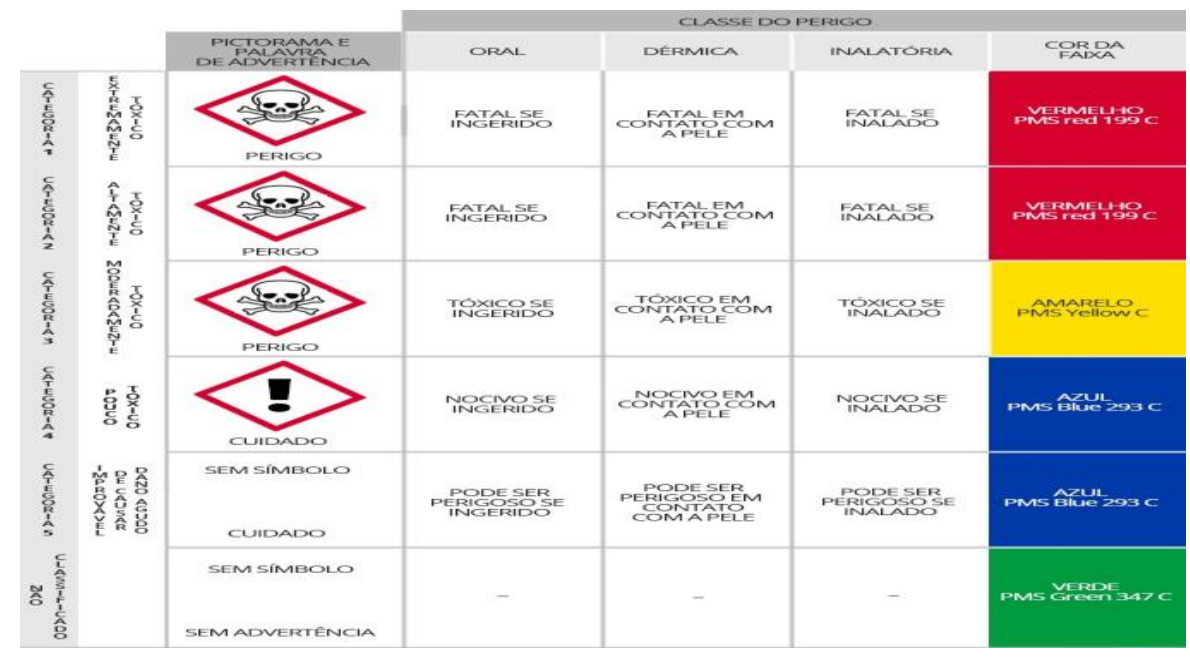

Figura 2 - Reclassificação toxicológica dos agrotóxicos.

Fonte: Brasil. (2019). Reclassificação toxicológica dos agrotóxicos. Brasília: Agência Nacional De Vigilância Sanitária-ANVISA. Disponível em: http://portal.anvisa.gov.br/noticias. Consultado em 28 de agosto de 2020.

Com isso, produtos considerados "moderadamente tóxicos", "pouco tóxicos" ou "improváveis de causar dano agudo" não terão o símbolo no rótulo, o que pode ser considerado prejudicial ao acompanhamento pela sociedade de possíveis contaminações pelos produtos comercializados a partir da implantação da nova classificação. 


\subsection{Importância dos Pequenos Produtores Rurais na Segurança Alimentar do Brasil}

Os pequenos produtores rurais são responsáveis por boa parte dos alimentos que chega às mesas dos brasileiros.

A agricultura familiar responde por cerca de $70 \%$ dos alimentos consumidos em todo 0 País, sendo o pequeno produtor rural responsável por grande parte da cadeia produtiva que abastece o mercado brasileiro, contribuindo com: mandioca (87\%), feijão $(70 \%)$, carne suína $(59 \%)$, leite $(58 \%)$, carne de aves $(50 \%)$ e milho (46\%), que são alguns exemplos de grupos de alimentos com forte presença da agricultura familiar na produção.

E atividade da irrigação foi um dos principais responsáveis pelo aumento da produtividade do setor agrícola nas últimas décadas, o que interferiu não somente sobre o aumento da oferta de alimentos exemplificado acima (Freitas, 2020).

Nesse contexto apresenta-se a figura do pequeno produtor rural irrigante, que de acordo com a Lei no 12.787, de 11 de janeiro de 2013 - dispõe sobre a Política Nacional de Irrigação - define agricultor irrigante como a pessoa física ou jurídica que exerce a atividade da agricultura irrigada, que é a atividade econômica que explora culturas agrícolas, florestais e ornamentais e pastagens, bem como atividades agropecuárias afins, com o uso de técnicas de irrigação e drenagem.

Essa Lei define também que um Projeto de Irrigação é um sistema planejado para o suprimento ou a drenagem de água em empreendimento de agricultura irrigada, de modo programado, em quantidade e qualidade, podendo ser composto por estruturas e equipamentos de uso individual ou coletivo de captação, adução, armazenamento, distribuição e aplicação de água.

Segundo Freitas (2010), é característico de grandes projetos de produção agrícolas irrigadas (Projetos Públicos de Irrigação-PPIs), que suas implementações e desenvolvimento operacional das atividades agrícolas irrigadas estejam associadas à geração de uma série de impactos adversos sobre o meio ambiente e, principalmente, ao homem, os quais só podem ser minorados através da incorporação de medidas de proteção ambiental e segurança das atividades laborais desse trabalhador rural por parte das empresas e/ou empreendedores agrícolas, o que poderá ser garantido pela ação eficiente dos técnicos e Engenheiros de Segurança do Trabalho.

Nesse contexto, relevante são as considerações de Vasconcellos e Gaze (2009), que afirmam que trabalho e ambiente estabelecem entre si uma relação indissociável. 
Dando ênfase, mais ainda, de que as doenças do trabalho, não podem ser analisadas de forma dissociada dos processos em que estão envolvidas.

Quando analisadas somente sob as esferas clínica, epidemiológica, geram classificações e sistematizações sobre o processo produtivo que não se relacionam entre si e não incorporam a variável integralidade, um dos pilares do modelo de atenção à saúde dos trabalhadores.

Assim, corroboramos com as ponderações de Costa (2006) no qual o mesmo afirma que as políticas econômicas atuais se mostram mais voltadas para atender aos interesses específicos de alguns setores da produção do que se dedicar ao atendimento das necessidades fundamentais dos consumidores como um modo global.

Nesse sentido, a produção de alimentos estará sempre direcionada a manter a alta produtividade e lucro numa lógica que atenda às exigências de mercados específicos, sem nenhuma preocupação de garantir segurança laboral ao integrante mais importante da cadeia de produção, o trabalhador rural.

\subsection{A Engenharia de Segurança do Trabalho}

De acordo com o Bureau Internacional do Trabalho (2009, p.01), a saúde e segurança do trabalhador como:

A promoção e a manutenção dos mais elevados níveis de bemestar físico, mental e social dos trabalhadores de todos os setores de atividade; a prevenção para os trabalhadores de efeitos adversos para a saúde decorrentes das suas condições de trabalho; a proteção dos trabalhadores no seu emprego perante os riscos resultantes de condições prejudiciais à saúde; a colocação e a manutenção de trabalhadores num ambiente de trabalho ajustado às suas necessidades físicas e mentais; a adaptação do trabalho ao homem. 
No Brasil, a segurança do trabalho enquanto prática legal, iniciou de forma oficial a partir de 1921, quando foi criada a inspeção do trabalho.

Na década de 1930, na era Vargas, foi instruído o Departamento Nacional do Trabalho, que entre várias de suas atribuições, tinha a defesa de condições adequadas para os trabalhadores urbanos e rurais (Bersot, 2020).

Considerada como resultante de um conjunto de ciências e tecnologias a Engenharia de Segurança do Trabalho tem como atuação basilar à proteção do trabalhador no seu local de trabalho e prima pela eliminação de acidentes e doenças ocupacionais.

Segundo Bersot (2020) o Engenheiro de Segurança do Trabalho cumpre um destacado no gerenciamento do ambiente de trabalho, seja coordenando equipes multiprofissionais, seja desenvolvendo projetos e ações preventivas, ou mesmo atuando como Perito Trabalhista.

Nesse ínterim, ressalta-se a importância desse profissional como responsável por coordenar e efetuar análise de projetos a serem implantados, em conjunto com as áreas técnicas, recomendando alterações, visando eliminar ou minimizar riscos de acidentes e doenças ocupacionais (Bersot, 2020).

Nesse contexto, elencamos as normas do Conselho Federal de Engenharia e Agronomia - CONFEA, que em seu Art. 4ํㅡㄹ dispõe sobre o exercício profissional, o registro e as atividades do Engenheiro de Segurança do Trabalho, definindo as suas atribuições:

- Supervisionar, coordenar e orientar tecnicamente os serviços de Engenharia de Segurança Trabalho;

- Estudar as condições de segurança dos locais de trabalho e das instalações e equipamentos, com vistas especialmente aos problemas de controle de risco, controle de poluição, higiene do trabalho, ergonomia, proteção contra incêndio e saneamento;

- Planejar e desenvolver a implantação de técnicas relativas a gerenciamento e controle de riscos;

- Vistoriar, avaliar, realizar perícias, arbitrar, emitir parecer, laudos técnicos e indicar medidas de controle sobre grau de exposição e agentes agressivos de riscos físicos, químicos e biológicos, tais como: poluentes atmosféricos, ruídos, calor radiação em geral e pressões anormais, caracterizando as atividades, operações e locais insalubres e perigosos; 
- Analisar riscos, acidentes e falhas, investigando causas, propondo medidas preventivas e corretivas e orientando trabalhos estatísticos, inclusive com respeito a custos;

- Propor políticas, programas, normas e regulamentos de Segurança do Trabalho, zelando pela sua observância;

- Elaborar projetos de sistemas de segurança e assessorar a elaboração de projetos de obras, instalações e equipamentos, opinando do ponto de vista da Engenharia de Segurança;

- Estudar instalações, máquinas e equipamentos, identificando seus pontos de risco e projetando dispositivos de Segurança;

- Projetar sistemas de proteção contra incêndio, coordenar atividades de combate a incêndio e de salvamento e elaborar planos para emergência e catástrofes;

- Inspecionar locais de trabalho no que se relaciona com a Segurança do Trabalho, delimitando áreas de periculosidade;

- Especificar, controlar e fiscalizar sistemas de proteção coletiva e equipamentos de segurança, inclusive os de proteção individual e os de proteção contra incêndio, assegurando-se de sua qualidade e eficiência;

- Opinar e participar da especificação para aquisição de substâncias e equipamentos cuja manipulação, armazenamento, transporte ou funcionamento possam apresentar riscos, acompanhando o controle do recebimento e da expedição;

- Elaborar planos destinados a criar e desenvolver a prevenção de acidentes, promovendo a instalação de comissões e thes assessorando no respectivo funcionamento;

- Orientar o treinamento específico de segurança do trabalho e assessorar a elaboração de programas de treinamento geral, no que diz respeito à Segurança do Trabalho;

- Acompanhar a execução de obras e serviços decorrentes da adoção de medidas de segurança, quando a complexidade dos trabalhos a executar assim o exigir;

- Colaborar na fixação de requisitos de aptidão para o exercício de funções, apontando os riscos decorrentes desses exercícios;

- Propor medidas preventivas no campo de Segurança do Trabalho, em face do conhecimento da natureza e gravidade das lesões provenientes do Acidente de Trabalho, incluídas as doenças do trabalho;

- Informar aos trabalhadores e à comunidade, diretamente ou por meio de seus representantes, as condições que possam trazer 
danos à sua integridade e as medidas que eliminam ou atenuam estes riscos e que deverão ser tomadas (Brasil, 1987, p. 21.117).

A Constituição Brasileira de 1988 foi de suma importância para a efetivação das normas de segurança do trabalho. Dentre os direitos sociais garantidos, o direito a saúde e a segurança dos trabalhadores estão assegurados, de acordo com 0 artigo $7^{\circ}$, inciso XXII explicita: "redução dos riscos inerentes ao trabalho, por meio de normas de saúde, higiene e segurança (Brasil, 1988, p. 05)".

\subsection{As Normas Regulamentadoras}

O monitoramento permanente das condições de trabalho e da disponibilização de equipamentos para emergência e de proteção ao trabalhador é de responsabilidade do profissional da Segurança do Trabalho, que deve averiguar permanentemente o que está preconizado na legislação e, principalmente, o que está explícito nas 37 Normas Regulamentadoras que regem as condições de trabalho das mais variadas especialidades.

Nesse sentido, de acordo com a ENIT - Escola Nacional da Inspeção do Trabalho (2020), as Normas Regulamentadoras estão assim dispostas:

- NR-1 Disposições gerais;

- NR-2 Inspeção prévia;

- NR-3 Embargo ou interdição;

- NR-4 Serviços Especializados em Engenharia de Segurança e em Medicina do Trabalho (SESMT);

- NR-5 Comissão Interna de Prevenção de Acidentes (CIPA);

- NR-6 Equipamento de Proteção Individual;

- NR-7 Programa de controle médico e saúde ocupacional (PCMSO); NR-8 Edificações;

- NR-9 Programa de prevenção de acidentes e riscos ambientais (PPRA);

- NR-10 Segurança em instalações e serviços em eletricidade;

- NR-11Transporte, movimentação, armazenagem e manuseio de Materiais;

- NR-12 Máquinas e equipamentos;

- NR-13 Caldeiras e vasos de pressão; 
- NR-14 Fornos;

- NR-15 Atividades e operações insalubres;

- NR-16 Atividades e operações perigosas com radiações ionizantes ou substâncias radioativas atividades/áreas de risco;

- NR-17 Ergonomia;

- NR-18 Condições e meio ambiente de trabalho na indústria da construção;

- NR-19 Explosivos;

- NR-20 Líquidos combustíveis e inflamáveis;

- NR-21 Trabalho a céu aberto;

- NR-22 Segurança e saúde ocupacional da mineração;

- NR-23 Proteção contra incêndios;

- NR-24 Condições sanitárias e de conforto nos locais de trabalho;

- NR-25 Resíduos industriais;

- NR-26 Sinalização de segurança;

- NR-27 Registro profissional do técnico de segurança do trabalho no Ministério do Trabalho;

- NR-28 Fiscalização e penalidades;

- NR-29 Segurança e saúde no trabalho portuário;

- NR-30 Segurança e saúde no trabalho aquaviário;

- NR-31 Segurança e saúde no trabalho na agricultura, pecuária, silvicultura, exploração florestal e aquicultura;

- NR-32 Segurança e saúde no trabalho em serviços de saúde;

- NR-33 Segurança e saúde nos trabalhos de espaços confinados;

- NR-34 Condições e meio ambiente de trabalho na indústria da construção e reparação naval;

- NR-35 Trabalho em altura;

- NR-36 Segurança e saúde no trabalho em empresas de abate e processamento de carnes e derivados.

- NR-37 Segurança e saúde em plataformas de petróleo (ENIT, 2020, p.01).

No caso específico deste trabalho enfatizou-se a NR 31, seus objetivos, diretrizes e campos de aplicação. A seguir apresenta-se todo conteúdo desta norma. 
3.7.1 NR 31 - Norma regulamentadora de segurança e saúde no trabalho na agricultura, pecuária, silvicultura, exploração florestal e aquicultura (ENIT, 2020).

- Estabelece os preceitos a serem observados na organização e no ambiente de trabalho, de forma a tornar compatível o planejamento e o desenvolvimento das atividades da agricultura e atividades assemelhadas com a segurança e saúde e o meio ambiente do trabalho.

- Se aplica a quaisquer atividades da agricultura, pecuária, silvicultura, exploração florestal e aquicultura.

- Também se aplica às atividades de exploração industrial desenvolvidas em estabelecimentos agrários.

\section{Obrigações do Empregador Rural}

- Garantir adequadas condições de trabalho, higiene e conforto para todos os trabalhadores;

- Realizar avaliações dos riscos para a segurança e saúde dos trabalhadores e, com base nos resultados, adotar medidas de prevenção e proteção para garantir que todas as atividades, lugares de trabalho, máquinas, equipamentos, ferramentas e processos produtivos sejam seguros e em conformidade com as normas de segurança e saúde;

- Promover melhorias nos ambientes e nas condições de trabalho, de forma a preservar o nível de segurança e saúde dos trabalhadores;

- Cumprir e fazer cumprir as disposições legais em segurança e saúde no trabalho;

- Analisar, junto com a CIPATR, as causas dos acidentes e as doenças relacionadas ao trabalho;

- Assegurar a divulgação de direitos, deveres e obrigações que os trabalhadores devam conhecer em matéria de segurança e saúde no trabalho;

- Adotar os procedimentos necessários quando da ocorrência de acidentes e doenças do trabalho, inclusive remoção acidentado;

- Assegurar que se forneça aos trabalhadores instruções compreensíveis em matéria de segurança e saúde, bem como toda orientação e supervisão necessárias ao trabalho seguro;

- Garantir participação dos trabalhadores nos programas de controles de riscos (CIPATR);

- Informar os riscos decorrentes do trabalho e as medidas de proteção implantadas, inclusive em relação a novas tecnologias adotadas pelo empregador; resultados de seus exames médicos e avaliações ambientais dos locais de trabalho;

- Permitir que representante de trabalhadores acompanhe as fiscalizações em SST;

- Adotar medidas de avaliação e gestão dos riscos com a seguinte ordem de prioridade: 
1. Eliminação dos riscos;

2. Controle de riscos na fonte;

3. Redução do risco ao mínimo através da introdução de medidas técnicas ou organizacionais e de práticas seguras inclusive através de capacitação;

4. Adoção de medidas de proteção pessoal, sem ônus para o trabalhador, de forma a complementar ou caso ainda persistam temporariamente fatores de risco

5. EPIs

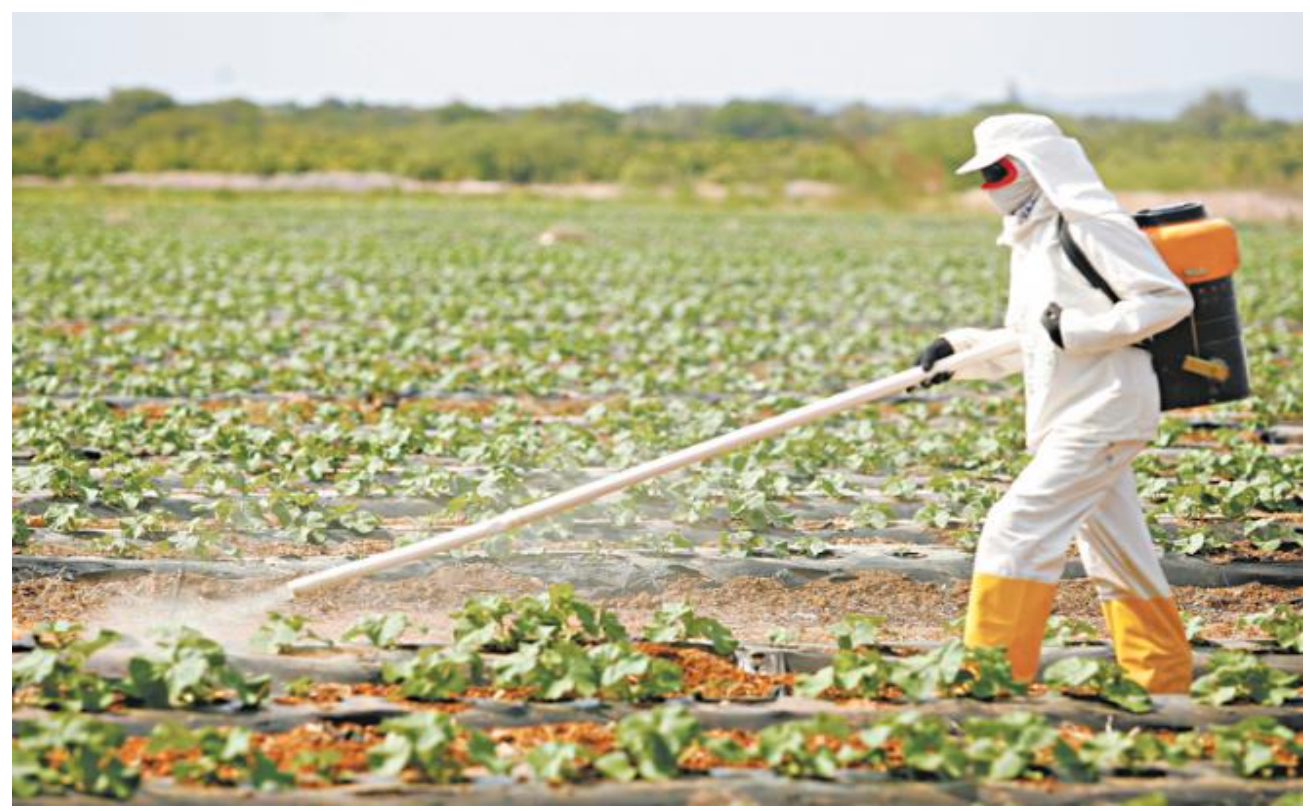

Figura 3 - Trabalhador do campo utilizando EPI.

Fonte: Cipa \& Incêndio. (2017). Seminário aborda requisitos de SST no trabalho agrícola. São Paulo: CIPA.

\section{Deveres do Trabalhador Rural}

- Cumprir as determinações sobre as formas seguras de desenvolver suas atividades, especialmente quanto às Ordens de Serviço para esse fim;

- Adotar as medidas de proteção determinadas pelo empregador, em conformidade com a Norma (inclusive EPI), sob pena de constituir ato faltoso a recusa injustificada;

- Submeter-se aos exames médicos previstos. 
- Colaborar com a empresa na adequada aplicação da NR-31.

\section{Direitos do Trabalhador Rural}

- Ambientes de trabalho, seguros e saudáveis;

- Ser consultados, através de seus representantes na CIPATR (Comissão Interna de Prevenção de Acidentes do Trabalho Rural), sobre as medidas de prevenção que serão adotadas;

- Escolher sua representação

- Informar situações de risco grave e iminente para que sejam tomadas as medidas de correção adequadas, interrompendo o trabalho se necessário;

- Receber instruções em matéria de segurança e saúde e orientação para atuar no

\section{Agrotóxicos, adjuvantes e produtos afins de acordo com a NR 35}

- Trabalhadores em exposição direta, os que manipulam os agrotóxicos e produtos afins, em qualquer uma das etapas de armazenamento, transporte, preparo, aplicação, descarte, e descontaminação de equipamentos e vestimentas;

- Trabalhadores em exposição indireta, os que não manipulam diretamente os agrotóxicos, adjuvantes e produtos afins, mas circulam e desempenham suas atividades de trabalho em áreas vizinhas aos locais onde se faz a manipulação dos agrotóxicos em qualquer uma das etapas de armazenamento, transporte, preparo, aplicação e descarte, e descontaminação de equipamentos e vestimentas, e ou ainda os que desempenham atividades de trabalho em áreas recém-tratadas.

- Proibido o uso de substâncias não autorizadas.

- Vedada a exposição direta de <menores de 18 e > 60 anos, mesmo protegidos e de mulheres grávidas.

- Proibido o acesso desprotegido em áreas recém-tratadas, antes do término do intervalo de reentrada (específico para cada produto).

\section{Obrigações do Empregador Rural quanto a utilização de Agrotóxicos e afins}

- Fornecer equipamentos de proteção individual e vestimentas adequadas aos riscos, que não propiciem desconforto térmico prejudicial ao trabalhador; em perfeitas condições de uso e devidamente higienizados, responsabilizando-se pela descontaminação dos mesmos ao final de cada jornada de trabalho, e substituindo-os sempre que necessário; 
- Orientar quanto ao uso correto dos dispositivos de proteção;

- Disponibilizar um local adequado para a guarda da roupa de uso pessoal;

- Fornecer água, sabão e toalhas para higiene pessoal;

- Garantir que nenhum dispositivo de proteção ou vestimenta contaminada seja levado para fora do ambiente de trabalho;

- Garantir que nenhum dispositivo ou vestimenta de proteção seja reutilizado antes da devida descontaminação;

- Vedar o uso de roupas pessoais quando da aplicação de agrotóxicos e a manipulação em desacordo com receita agronômica.

- Proibir a entrada e permanência de qualquer pessoa na área a ser tratada durante a pulverização aérea.

- Deve proporcionar capacitação sobre prevenção de acidentes com agrotóxicos a todos os trabalhadores possíveis de serem expostos, mediante programa específico, e com informações técnicas suficientes aos que manipulam agrotóxicos.

Percebe-se, nessa relação, entre o uso de agrotóxicos e o possível adoecimento do trabalhador rural, que mesmo com a necessidade de uso deste tipo de produto nas mais diversas esferas das atividades agrícolas ou mesmo em controles sanitárias, a necessidade de intervenções corretas e eficazes que garantam segurança em todas as fazes de execução da aplicação de qualquer um desses defensivos, e que, os Engenheiros de Segurança do Trabalho podem ter ação ativa e efetiva nessas ações de manejo e controle, assegurando condições salubres a todos os possíveis envolvidos nos processos.

\section{CONSIDERAÇÕES FINAIS}

Ao tempo em que a atividade de agricultura se torna essencial à sociedade moderna, com todos os benefícios econômicos e sociais proporcionados por ela, principalmente no quesito segurança alimentar da população, exigindo que, rotineiramente, que se faça uso de novas tecnologias agrícolas.

No caso específico, da agricultura irrigada, não se pode desprezar os pequenos produtores rurais irrigantes, pois são eles os responsáveis por boa parte dos alimentos que chega às mesas dos brasileiros.

Assim, mesmo que o crescimento de forma exponencial da população exija um crescimento da produção agrícola na mesma proporção, tornando o uso dos defensivos agrícolas praticamente inevitável, torna-se imperioso aos Engenheiros de Segurança do Trabalho, detentores do conhecimento e aplicabilidades das normas legais de garantias da salubridade das condições de trabalho, assegurar àqueles que necessitam de nossa orientação 
técnica e proteção, condições para o exercício pleno e seguro das atividades laborais de todos os envolvidos num sistema de produção agrícola, principalmente os pequenos produtores rurais.

Pelo exposto infere-se que uma adequada gestão das ações de segurança na execução das principais atividades exercidas no meio rural exige uma constante busca no sentido de adequar e sobretudo melhorar as condições de trabalho daqueles que exercem suas atividades no campo.

Nesse contexto, o profissional responsável pela implementação dessas ações deve ter a devida noção do que pode ocorrer em cada setor de trabalho, identificando e melhorando as condições laborais em cada posto de serviço, bem como evitar os riscos, verificando as condições de proteção de cada local para evitar erros fatais.

Ações de monitoramento e a disponibilização de equipamentos de emergência em locais pré-determinados podem evitar muitos acidentes e é responsabilidade formal do responsável pela segurança do trabalho.

Portanto, considerando que é dever do Engenheiro de Segurança do Trabalho voltar-se precipuamente para a proteção do trabalhador em todas as unidades laborais no que se refere a questões de segurança, tendo como princípio básico evitar acidentes, sua atuação na segurança laboral de todos trabalhadores, em especial, aqueles trabalhadores que desenvolvem suas atividades no meio rural, no caso específico são os que exercem suas atividades no âmbito de projetos públicos de irrigação.

Por fim diante da realidade atual de desenvolvimento de nossas atividades agrícolas no presente e no futuro próximo, observa-se, esse profissional, como um profissional garantidor efetivo da segurança laboral no meio rural.

\section{REFERÊNCIAS}

Brasil. (1987). Resolução № 325. Brasília: Diário Oficial da União.

Brasil. (1988). Decreto № 4.074, de 04 de dezembro de 2002, regulamenta a Lei oo 7.802 de 11 de julho de 1989. Publicado no DOU do dia 04 de janeiro de 2002. Brasília: Diário Oficial da União.

Brasil. (1988). Lei no 7.802 de 11 de julho de 1989. Publicado no DOU do dia 12 de janeiro de 1989. Brasília: Diário Oficial da União. 
Brasil. (1988). Constituição da República Federativa do Brasil. Brasília: Diário Oficial da União.

Brasil. (2013). Documento orientador para a implementação da vigilância em saúde de populações expostas a agrotóxicos. Brasília: Ministério da Saúde (BR).

Brasil. (2019). Reclassificação toxicológica dos agrotóxicos. Brasília: Agência Nacional De Vigilância Sanitária-ANVISA. Disponível em: https://www.gov.br/anvisa/pt-br. Consultado em 28 de agosto de 2020.

Bombardi L. M. (2017). Geografia do uso de agrotóxicos no Brasil e conexões com a União Europeia. São Paulo: Laboratório de Geografia Agrária - FFLCH - USP.

Bersot, K. (2020). Qual é a Importância da Engenharia de Segurança do Trabalho. São Paulo: UNASP.

Bureau Internacional do Trabalho. (2009). Introdução à saúde e segurança no trabalho. Genebra.

Carneiro, Fernando; Pignati, W.; Rigotto, R. M.; Augusto, L. G. S.; Rizollo, A.; Faria, N. M. X.; Alexandre V. P.; Friedrich, K.; Mello M. S. C. D et al. (2015). Dossiê ABRASCO: um alerta sobre os impactos dos agrotóxicos na saúde. Rio de Janeiro: EPSJV; São Paulo: Expressão Popular.

Cipa \& Incêndio. (2017). Seminário aborda requisitos de SST no trabalho agrícola. São Paulo: CIPA.

Costa, Francisco de Assis. (2006). Arranjos produtivos locais e o planejamento do desenvolvimento regional na Amazônia. In: Oliveira, José Ademir de et al. Amazônia: políticas públicas e diversidade cultural. Rio de Janeiro: Garamond.

ENIT - Escola Nacional da Inspeção do Trabalho. (2020). Normas Regulamentadoras (NRs) Disponível em: https://enit.trabalho.gov.br/portal/index.php/seguranca-e-saude-notrabalho/sst-menu/sst-normatizacao/sst-nr-portugues. Consultado em 28 de agosto de 2020.

ENIT - Escola Nacional da Inspeção do Trabalho. (2020). Norma Reguladora NR 31 Norma regulamentadora de segurança e saúde no trabalho na agricultura, pecuária, silvicultura, exploração florestal e aquicultura. Disponível em: 
https://enit.trabalho.gov.br/portal/index.php/seguranca-e-saude-no-trabalho/sstmenu/sst-normatizacao/sst-nr-portugues. Consultado em 28 de agosto de 2020.

Freitas, B. B. C. (2010). Marcas da modernização da agricultura no território do Perímetro Irrigado Jaguaribe-Apodi: uma face da atual reestruturação socioespacial do Ceará. Dissertação Mestrado. Fortaleza: Universidade Estadual do Ceará.

Freitas, E. de. (2020). Importância dos pequenos produtores no Brasil; Brasil Escola. Disponível em: https://brasilescola.uol.com.br/brasil/importancia-dos-pequenosprodutores-no-brasil.htm. Consultado em 28 de agosto de 2020.

Moraes, R. F. (2019). Agrotóxicos no Brasil: Padrões de uso, política da regulação e prevenção da captura regulatória. Brasília: IPEA.

Santos, Vanessa Sardinha dos. (2020). Contaminação ambiental por agrotóxicos. Brasil Escola. Disponível em: https://brasilescola.uol.com.br/biologia/contaminacao-ambientalpor-agrotoxicos.htm. Consultada em 12 de julho de 2020.

Soares, Wagner; Porto, Marcelo. (2012). Atividade agrícola e externalidade ambiental: uma análise a partir do uso de agrotóxicos no cerrado brasileiro. Ciência \& Saúde Coletiva, Rio de Janeiro, v. 12, n. 1, p. 38-43. ISSN 1678-4561.

Sousa, Rafaela. (2020). Agrotóxicos. Brasil Escola. Disponível em: https://brasilescola.uol.com.br/geografia/agrotoxicos.htm. Consultado em 12 de julho de 2020.

Tooge, Rikardy. 2020. Governo libera o registro de 31 agrotóxicos genéricos para uso dos agricultores. São Paulo: G1. Disponível em: https://g1.globo.com/economia/agronegocios/noticia/2020/09/23/governo-libera-oregistro-de-31-agrotoxicos-genericos-para-uso-dos-agricultores.ghtml. Consultado em: 23 de setembro de 2020.

Vasconcellos, L. C. F. De.; Gaze, R. (2009). Integridade e doenças dos trabalhadores - O método de Bernardino Ramazzini. Rio de Janeiro: Fundação Oswaldo Cruz.

Vasconcelos, Y. (2018). Agrotóxicos na berlinda. Revista Pesquisa FAPESP, Edição 271. Setembro. ISSN 0101-3262. 